\title{
ARTICLE
}

\section{Cultivating Digitization Competencies}

\author{
A Case Study in Leveraging Grants as Learning Opportunities in Libraries and Archives \\ Gayle O'Hara, Emily Lapworth, and Cory Lampert
}

\section{ABSTRACT}

This article is a case study of how six digitization competencies were developed and disseminated via grant-funded digitization projects at the University of Nevada, Las Vegas Libraries Special Collections and Archives. The six competencies are project planning, grant writing, project management, metadata, digital capture, and digital asset management. The authors will introduce each competency, discuss why it is important, and describe how it was developed during the course of the grant project, as well as how it was taught in a workshop environment. The differences in competency development for three different stakeholder groups will be examined: early career grant staff gaining on-the-job experience; experienced digital collections librarians experimenting and innovating; and a statewide audience of cultural heritage professionals attending grant-sponsored workshops.

\section{INTRODUCTION}

Digitization of cultural heritage resources is commonly viewed as an important and necessary task for libraries, archives, and museums. There are many reasons for engaging in digitization projects and creating digital collections, including providing increased access to unique collections, preserving fragile records, raising the global profile of the institution, meeting user demand, and supporting the teaching, learning, and research needs of host institutions. In addition, there is an expectation among the public that research resources are digitized and available online.

From the perspective of librarians and archivists, digitization of special collections and archives materials involves more than just reformatting analog materials into a digital format (this article uses the term "digitization" to refer to the entire lifecycle of digitization projects involving special collections and archives materials, from planning to preservation). Materials must be selected and prepared, the digital surrogates must be described and preserved, and access must be provided to the appropriate audiences. Digitization work is often project-based, since each set of materials to be digitized may require different equipment, specifications, approaches, or workflows.

Digitization projects and workflows can be a solo affair, a temporary project team, or a permanent functional area complete with staff specializing in activities such as project management, grantwriting, web development, or metadata. Staff learning needs will significantly vary depending on organizational characteristics, assigned roles, project specifications, and motivation of individuals.

Overall, the libraries' and archives' profession-wide approach to teaching and developing digitization competencies is somewhat haphazard. There are many methods to learn about digitization, including self-study of published resources, online tutorials and resources, conference presentations, workshops, continuing education courses, and masters in library and information

Gayle O'Hara (gayle.ohara@wsu.edu) is Manuscripts Librarian, Washington State University. Emily Lapworth (emily.lapworth@unlv.edu) is Digital Special Collections \& Archives Librarian, University of Nevada Las Vegas. Cory Lampert (cory.lampert@unlv.edu) is Head of Digital Collections, University of Nevada Las Vegas. (c) 2020. 
science (MLIS) program classes. ${ }^{1}$ In many graduate school programs there has been a move toward integrating digital library theory and practice, but courses are necessarily broad in nature, and not every student will be required or have the opportunity to complete a practicum or internship while studying. This can make it difficult for new librarians to identify which skills are most in demand and which type of self-study is most useful for the job market. Identifying key competencies, and how to acquire them, may be helpful in supporting new librarians as they make the jump from graduate education to their first professional position, but it is not a challenge limited to newer professionals. Even seasoned librarians and archivists, with practical experience in their portfolio, may find that their local experience does not translate to different organizations, is too broad for a particular project, or is not deep enough for them to lead the initiation of a new digitization program.

The Digital Collections department at the University of Nevada, Las Vegas (UNLV) has a decadelong record of hiring early career librarians for grant-funded projects, providing them with opportunities to develop digitization competencies on the job. From 2017 to 2019, UNLV's Digital Collections department completed two grant-funded digitization projects that specifically set out goals to contribute to competency development for multiple stakeholders. Early career project managers learned, practiced, and refined skills; the department experimented and innovated its own workflows; and the project team held two workshops to contribute to the development of digitization competencies throughout the state. The six main competencies that were developed during the grant projects are project planning, grant writing, project management, metadata, digital capture, and digital asset management. The authors, who were members of the grant project teams, will discuss the six competencies in this article. Using the grant projects as a case study, they will describe each competency and share how it was used and developed within the project team via on-the-job learning, and within the state via the statewide workshops.

\section{LITERATURE REVIEW}

The idea of professional competencies for librarians and archivists is well-established and documented in academic literature, and defined competencies are recognized as valuable tools for education, recruitment, professional development, and evaluation. Drawing from organizational project management literature, Daniel, Oliver, and Jamieson define competency as the ability to apply combined knowledge, skills, and abilities in service of a measurable and observable goal. ${ }^{2}$ In the United States, the American Library Association (ALA) defines "Core Competencies of Librarianship" and "Competencies for Special Collections Professionals." 3 The Competency Framework of the Archives \& Records Association of the United Kingdom and Ireland (ARA) describes five levels of experience: novice, beginner, competent, proficient, and expert/authoritative. ${ }^{4}$ ARA's recognition of the varying dimensions of competency is a helpful guide, and aligns with the reality of different levels of expertise. However, the competencies identified by ALA, ARA, and other similar professional organizations are necessarily broad; competencies for specific library roles are harder to generalize and define.

In order to identify the knowledge, skills, and abilities required of "digital librarians," researchers such as Choi and Rasmussen analyzed job announcements and surveyed practitioners. ${ }^{5}$ Job announcement analysis shows that there is no single definition of a digital librarian; instead digital librarian positions consist of many varied roles and responsibilities in almost infinite combinations. The competencies discussed in this article (project planning, grant writing, project management, metadata, digital capture, and digital asset management) were locally important to 
UNLV's digitization projects, but they also align with the competencies identified in previous research. In their study of projects undertaken in the National Digital Stewardship Residency program (NDSR), Blumenthal et al. found that project management skills and technical skills (including metadata, workflow enhancement/development, digital asset management, and digitization) were important. ${ }^{6}$ The level of required technical competency tended to vary by project but workflow enhancement stood out as a universally important skill. A 2019 analysis of the latest career trends for information professionals by San Jose State University's (SJSU) iSchool noted that there is increasing demand for project management skills across all career types. ${ }^{7}$ This usually encompasses the ability to organize complex tasks and collaborate with other departments or institutions in service of a shared goal. SJSU also cited "new technologies" as a necessary skill. However, they specified that this refers to "all iterations relating to interest in, familiarity with, or experience with new and emerging technologies" (emphasis in the original). In Choi and Rasmussen's article analyzing job ads, the authors note that many of the frequently stated job requirements tend to be vaguely described or cover broad areas, including current trends in digital libraries, competency on general technological knowledge, and the current state of information technology as three most frequently mentioned competencies. ${ }^{8}$ Digital asset management, digital scanning, digital preservation, and metadata were some of the specific technical skills desired, as well as project management, planning, and organization. Research shows that the more generic the competencies, the more broadly applicable they are; but specific competencies depend on the local environment, the role of the position, and the variables of the project or responsibilities.

The wide range of competencies required by the digital library field paired with the specificity of local implementation requires new librarians and archivists to seek out learning opportunities that target both theory and practice. In fact, one of the most important aspects of practical experience is the benefit gained by experiencing the concepts in real-world situations that require decision-making, iteration, and sometimes even failure. The education field points to the Kolb model of experiential learning, a cycle that is composed of four elements: concrete experience, reflective observation, abstract conceptualization, and active experimentation. ${ }^{9}$ These elements mirror the process of learning observed in the grant case studies. New project staff are often trained to do tasks, then reflect upon what went well or was challenging. Then permanent staff in leadership roles encourage and facilitate discussions in abstract concepts such as the philosophy behind an organization's decision to prioritize efficiency or the concepts of creating authentic digital surrogates. While it may not happen in every project, within both grant cases, the final phase of the learning cycle was also reached as project staff and permanent employees worked together to move practice forward through testing, experimentation with new methods, and ultimately innovation of new models for digital library practices in the area of large-scale digitization.

Kolb's model can be useful throughout the library and archives field, as shown in the following example. The Federal Agencies Digital Guidelines Initiative (FADGI) started in 2007 as a collaboration of federal agencies seeking to articulate common sustainable practices and guidelines for digitized and born-digital cultural heritage resources. The FADGI website is a treasure trove of approved and recommended guidelines covering still image digitization, embedding metadata, project planning for digitization activities, and more. ${ }^{10}$ It essentially provides step-by-step guides for all aspects of digitization and is a tool that those interested or actively involved in digitization should be familiar with and consult on a regular basis. However, 
FADGI technical standards are relatively prescriptive, so organizations often have to decide how to implement them within their local environments, taking into consideration a wide range of variables. If every new digitization project manager conscientiously implemented the FADGI standards without associated institutional context, they could be investing their organization in long-term cost commitments that cannot be sustained over time or that do not meet the project goals. This scenario points to the need for hands-on experience and learning as outlined in the Kolb model. The digitization project manager may want to revisit the goals of the project (access vs. preservation, or both) and resource allocations (storage capacity, software and hardware specifications, staff time and expertise), and then pilot a subset of materials by capturing with the FADGI standard and calculating the storage sizes of the files and any associated workflows for long-term management. Through this small experiential exercise, much information can be gained, reflected upon, and then used to conceptualize how to proceed. Most of the tasks associated with digital library projects demand increasing competency over time to progress from enacting the technical standard in an organizational context, to revising it across projects or local environments, to educating others about the role of the standard, or to, at the highest levels of competency actively participate in the creation or revision of the standard itself as it changes over time. The ability to not only implement but also refine and even innovate comes from a process of mastery of the competency in question.

Experiential learning is an important method for developing and refining competencies from a novice to more expert level, but not all librarians and archivists have the opportunity to learn from more experienced colleagues on the job. Matusiak and Hu emphasize the importance but also the inconsistency of integrating experiential learning into MLIS programs. ${ }^{11}$ For those who do not gain practical experience in library school or on the job, workshops are an additional learning opportunity that can help professionals bridge the gap from written resources to local implementation. The Illinois Digitization Institute is one example described in detail by Maroso in $2005 .{ }^{12}$ Digital Directions is a conference that presents the "fundamentals of creating and managing digital collections" in two days. ${ }^{13}$ Other available workshops focus more closely on different aspects of digitization, such as metadata or preservation, or training for specific equipment via a vendor.

In the following examination of UNLV's digitization grant projects and workshops, the authors address six competencies that were either employed or developed by staff or have been identified in existing literature. These competencies may be viewed as critical building blocks for digitization projects and the authors address how they were developed to different levels of expertise and using different methods, experiential learning, and workshops.

\section{OVERVIEW OF GRANT PROJECTS}

UNLV's Digital Collections completed two grant projects with the main goals of: (1) the large-scale digitization of archival collections, (2) the development of large-scale digitization models and workflows that could be reused, and (3) statewide workshops to share those models and workflows with other libraries and archives institutions. Both projects were funded by Library Services \& Technology Act (LSTA) grants administered by the Nevada State Library and Archives. The first project, "Raising the Curtain: Large-Scale Digitization Models for Nevada Cultural Heritage," digitized mainly visual materials on the topic of Las Vegas entertainment, while the second project, "Building the Pipelines: Large-Scale Digitization Models for Nevada Cultural Heritage," digitized mostly text documents about water issues in southern Nevada. 
Digital Collections hired two types of temporary project-specific staff for the two digitization grants: project managers and student assistants. The project manager for each grant coordinated the day-to-day activities, such as preparation of the materials, digital capture, quality control, metadata, and ingest into the digital collection management system, as well as helping to fine-tune workflow documentation. The student assistants contributed to digital capture, quality control, metadata creation, and upload to the digital collection management system.

These grant projects are strong examples of experiential learning and competency development. Two of the authors were principal investigators (PIs) for both of the grants, and one author was the project manager for the second Building the Pipelines grant. At time of hire, the project manager for the second grant had experience working in special collections and archives but had not previously worked in a digital environment. One student assistant was hired for this project; she had already worked on the first large-scale digitization grant project in Digital Collections and was already familiar with the digitization workflow, as well as the hardware and software. Employing a student who had already experienced the concrete tasks (phase 1, "concrete experience" in the Kolb model) allowed her to help the new project staff as they could together perform "reflective observation" (phase 2) and learn from their compiled shared experience. The project PIs were intentional in designing opportunities for discussion. They regularly met with the student and project manager to help them understand what they were seeing and experiencing in the context of the organization's mission and the grant goals (Kolb's "abstract conceptualization"). The Building the Pipelines grant project facilitated each of them gaining more competency and moving to the next level while also helping the PIs learn through experimenting with new approaches (the final phase of "active experimentation"). The same experiential learning model was also successfully used for the first Raising the Curtain grant project.

As previously stated, conducting a day-long digitization workshop for Nevada libraries and archives was a goal of both large-scale digitization grant projects undertaken by UNLV Digital Collections. The Nevada Statewide Large-Scale Digitization Workshops, which were held towards the end of each grant period, were free for participants, and travel grants were available thanks to the grant funding. The workshops sought to provide an overview of large-scale digitization using UNLV projects as examples, as well as to provide practical advice related to developing digitization competencies. The first workshop that UNLV held in May 2018 consisted of presentations and discussions addressing the basics, methods, and challenges of large-scale digitization. The second workshop, held in May 2019, still shared what UNLV learned about large-scale digitization during the grant project, but widened the scope to address multiple important digitization competencies, whether the project is large or small.

\section{COMPETENCIES}

Whether presented in a project-based learning environment, a one-day workshop, or in a selfstudy scenario, learners can benefit from a clear understanding of what is meant by competencies in each of the areas that make up a successful digitization project. Below, the authors share the competencies most critical to success in the case study projects. These were also the competencies selected as priorities for the workshops. While expertise is not mandatory in all of the competencies in order to start a digitization project or apply for a grant, reflection and planning for each of these steps should be addressed prior to initiating any project. By identifying available resources (such as existing documentation, available staff with expertise to consult, or approval from a supervisor for a self-study plan) project managers can ensure that if there are any 
competency gaps, they will learn the needed competencies to carry out the project. In addition, throughout the learning process, interpersonal skills such as proactive communication, adaptability to change, flexibility in evolving job scope, and cultivation of comfort with ambiguity are all qualities that are just as necessary as any technical skill in mastering competency in digitization.

\section{Project Planning}

This competency can be defined as the ability to create a shared and documented vision and plan so that specifications, expectations, roles, goals, and timelines are considered in advance and clear to everyone involved. Planning for a digitization project is best approached holistically. The planning period is the time to consider all needed competencies and plan for their implementation.

Writing up a project plan is important, especially since digitization can involve many collaborators and stakeholders. Even if one is working alone, there are so many components, steps, and details involved in digitization projects that it is important to plan ahead for them and to document everything. Brainstorm and write down ideas and plans for the project, from the overall scope, goals, timelines, and roles, to the specific details of each component, including specifications and workflows for digital capture, metadata, access, preservation, assessment, and promotion (see Appendix A, "An overview of planning and implementing digitization projects"). The plan should be communicated, remain flexible, and be updated (or better yet, versioned) to document changes implemented during the project.

An important part of project planning is selecting materials for digitization. To develop competency in effectively selecting materials, a person should be familiar with the materials and the digitization process or collaborate closely with people who are. It is often not until one is in the weeds and discussing the nitty-gritty details of a project that the challenges and actual viability of digitizing specific materials become apparent. Format is a huge factor in digitization, as is description, and understanding how materials will be used. ${ }^{14}$ Digitizing a group of materials that can all be processed the same way is much easier than undertaking a project to digitize many different formats that require different digitization specifications, equipment, description, processing, etc. One must also take into account legal and ethical considerations. Successful selection of materials takes all factors into account and targets materials that fit with the overall goals and vision of a specific project. ${ }^{15}$

In the case of UNLV's grant projects, the head of Digital Collections and the Digital Collections librarian identified the main goals, developed tentative workflows, and authored the grant applications as co- PIs. The PIs had multiple years of experience planning and completing digitization projects, which they drew upon to plan these projects. They both started off developing their digitization competencies by completing pilot projects, developing workflows and writing grants to fund smaller-scale, highly curated "boutique" projects. As they honed their skills and the department's workflows over the years and the organization built the capacity and expertise to successfully scale up the rate of digitization, digital object production grew from one staff member using one scanner to digitize a couple hundred items in a year, to a robust department with a digitization lab that produces tens of thousands of digital surrogates per year.

The PIs documented the vision and goals of the projects in the grant applications, along with timelines, desired outcomes, the roles of the team members, and budgets. The grant application 
provided a structure to help with the bigger picture of project planning, and the Digital Collections librarian also used a template to create detailed digitization plans for the collections. The template was developed locally based on past experience planning and implementing digitization projects (see Appendix B for UNLV'S “digitization plan template”).

Project planning was completed prior to the hire of the project managers and student assistants. The project managers and student assistants were responsible for enacting the project plans, and during the projects they were empowered to adapt and improve upon the plans. The modelling provided by the PIs, coupled with the day-to-day experience of the project managers, led to the continuous improvement of and adaptation of workflows through experiential learning. The grant application and digitization plan, along with all of the prepared workflow documentation and tracking spreadsheets, provided a concrete example of how large digitization projects can successfully be planned. By implementing and refining the plans herself, the project manager gained direct experience and intimate knowledge of the plans, including what worked well and what did not. The project manager therefore developed competency in project planning to be able to create plans herself, and the PIs further refined their own planning skills, allowing them to plan for even larger or more complex projects in the future. Based on previous experience with projectbased learning, the PIs had already established a level of expertise at roughly level 4 in the ARA tiers. Level 5 includes innovation, which was a target of the grant project as it required the PIs not only to successfully map past experience to a new situation, but in cases where experiences did not map, gain new knowledge through experimentation.

The project team included project planning as a topic of the statewide digitization workshops, sharing digitization plan templates, finalized workflows, and other planning resources that aided in the successful completion of the grant projects. Building upon feedback from the first workshop in 2018 , the second one addressed the ability to create a digitization project plan of any scale, recognizing that many Nevada institutions do not have the ability to engage in large-scale projects. Despite the emphasis on the foundational importance of project planning, most attendees noted that they do not currently create detailed digitization plans prior to starting a project. Providing examples of plans, practical resources, sharing hands-on experiences, and welcoming discussion was helpful to participants, as indicated by feedback on the post-workshop survey. The workshop organizers scheduled time for participants to work on their own digitization plan, and also offered private consultations to help them, but many participants did not have a specific project in mind and did not seem ready to jump into the details of project planning during the workshop. Overall, these teaching strategies helped participants gain a better idea about how to plan digitization projects, but they do not match the experience of creating or implementing a plan oneself.

\section{Grant Writing}

All projects begin with an idea, but only a small fraction of possible projects are acted upon. This is due primarily to a scarcity of resources. Grant writing is not a necessary competency for all projects, but it is a valuable skill that can secure funding for projects that otherwise would not have been prioritized or possible. In its simplest form, a grant is a well-communicated idea with supporting rationale that effectively communicates why a project is a priority to undertake. ${ }^{16}$ Grant applications are usually composed of a narrative section that covers the main goals, a budget with associated costs for the project, letters of support from partners, and details about the project team leading the work. Even if a grant is not needed to undertake a project, the process of writing one often mirrors the very same decision-making that is necessary in the project planning 
step. Project planning is recommended for all digitization projects and it is nearly always required by external grant funders.

Grant writing can be undertaken alone, in a team, or (in larger institutions) as part of a research office or external funding program. In any case, it can be defined as the skill of writing text, calculating costs, and compiling relevant documentation to successfully propose projects for the award of external funding. Competency in grant writing requires excellent communication skills, including the ability to craft persuasive arguments advocating for the project and the analytical ability to interpret instructions and guidelines to ensure the project is in compliance with the funder's requirements. Often, grant writing involves several people: disciplinary experts, collaborative partners, commercial vendors or contractors, technicians, and advisory boards. Being able to facilitate discussions and coordinate actions is vital to wrangling the pieces of a large grant pre-award, as well as successful grant administration once funded. Grants are competitive in nature, so creativity and originality in framing of a problem can mean the difference between a highly ranked grant and one that is passed over by reviewers. One method to obtain competency in grant writing is to read as many grant proposals as possible, specifically targeting those for similar projects. ${ }^{17}$ In addition, some funders look for a panel of grant reviewers and seeking out opportunities to participate in these processes is a valuable education.

In the case of UNLV Digital Collections and the PIs, grant writing has been honed over time by some of the strategies mentioned above: reading other grant applications, serving on grant review panels, collaborating with other stakeholders, and communicating with the granting agency to understand criteria and solicit feedback. Although the grant proposal was written and the grant was secured prior to the hire of the project managers, the project managers were able to develop a thorough understanding of the grant process. By successfully completing the grant projects, in addition to reviewing the grant proposals, contributing to quarterly reports, and discussing the projects with the PIs and other stakeholders, the project managers gained valuable experience and understanding to inform their own future grant applications.

Given the scarcity of resources, the statewide digitization workshops made it a priority to address various aspects of locating grant opportunities, preparing to write proposals, seeking out collaborations to strengthen applications, and the mechanics and timelines to expect when applying for grants. One of the panel sessions in the workshops included a presentation by the state library's grant administrator, who provided an overview of the state process and what the board looks for when reviewing project proposals. Many participants found this particularly helpful because seeking out and applying for grants for digitization projects was not within their frame of reference, especially as many did not believe they had the requisite expertise in digitization. Awareness of a need, gathering information, and analyzing examples are some of the first steps in developing a competency. The workshops helped attendees take these first steps of developing competency in grant writing and management but fell short of actually helping them to write their own grants. In this case, however, it was appropriate since the attendees did not have specific projects in mind and likely needed to spend more time in the first stages of competency development before jumping into implementation. Workshops are most effective when the level of the content is appropriate to the level of expertise of the attendees.

\section{Project Management}

Project management training is not often specifically emphasized in MLIS programs. While there is literature on this topic, most people learn on the job. ${ }^{18}$ A successful project manager demonstrates 
mastery of this competency by taking responsibility and assuming leadership of the project throughout the process, even if they are not intimately involved in the day-to-day tasks. They often are responsible for hiring and training project team members as well as communicating and responding to project team members and stakeholders. While they are tracking and analyzing progress using appropriate metrics, they are often the one raising a red flag if the project is experiencing delays or challenges. Because they are responsible for ensuring the completion of the main goals of the project within the specified timeline, they often need to analyze bottlenecks and propose possible solutions in order to deliver high-quality results. Ideally, they learn from their experiences and also help other team members and the organization learn from experience. A key role of the project manager is not only to deliver the outputs, but to assess and analyze, both during the project, in order to make improvements, and after, in order to inform future projects. Therefore, investment in mentoring and supporting a project manager, whether a temporary or permanent staff member, can greatly influence how much learning takes place during the project and how that acquired knowledge is transferred to others.

Documentation is a key part of project management. This needs to happen at every interval of the project-while planning, during implementation, and at the conclusion. ${ }^{19}$ Documenting concrete data including the time spent on specific activities helps to plan cost predictions for future projects, as well as to make recommendations regarding future staffing and equipment. Mastering this competency involves planning, an eye for both details and the big picture, clarity, transparency, communication, and dedicated recordkeeping from the start of the project to the end.

Much like in project planning, the UNLV PIs had multiple years of experience stewarding projects from start to finish, which assisted them in on-the-job development of the project management competency. They were able to share with the project managers their accumulated years of learning experiences on both the projects, providing guidance on what to look for and how to comprehensively document the current digitization projects. This mentorship, combined with the experience of managing the day-to-day workings of the digitization projects, allowed the early career librarians to develop this competency. In addition, monthly project staff meetings, complemented by on the spot consultation when necessary, contributed to the ease of competency development.

During the statewide digitization workshops, the project teams discussed digitization project management and shared strategies and tools such as using Google Sheets and Trello to track workflows and progress. The teams also provided advice for aspects of project management such as managing student workers, troubleshooting equipment, transparent communication, and more. The project team chose to focus specifically on their own large-scale digitization experience because literature and resources about general and library project management are readily available. In addition, participants were encouraged to consider how their non-digitization experiences with project management could be translated to this kind of project as a way to encourage reflective learning based on their individual experience.

\section{Metadata}

Digitizing materials would not be a valuable endeavor without comparable investment in describing them with metadata that aids users in discovering and using the digital objects. Developing a project plan that includes metadata approaches is essential in scoping project work and resources. Metadata assignment and quality review is often a far more resource-intensive step 
than the process of digital capture. Metadata is one digitization competency that is robustly addressed in library school programs. Standards are well documented and examples of digital library metadata are easily accessible online. The importance of metadata to the library and archives profession means that many professionals already have a foundational knowledge. What makes metadata a difficult competency to master is the level of detail and specificity it entails, which makes the step from theory to practice challenging.

Metadata competencies require an understanding of recognized standards, the ability to interpret and apply them, and an awareness of metadata mobility including: reusability, interoperability, and flexibility for migration or transfer. ${ }^{20}$ Metadata-related skills require comfort moving along a wide spectrum of varied tasks, often toggling between awareness and understanding of high-level philosophical issues (such as inclusiveness of subject terms) and a laser-focused eye for detail to troubleshoot data issues (like correcting spreadsheets or code). Metadata work traverses several phases of the digitization lifecycle: from initial preparation of collections, during capture, through the ingest into systems, and over the long-term to maintain and preserve the assets.

Metadata quality itself is difficult to quantify, making this a competency that can be tricky to evaluate. Mastery can be indicated through the identification and study of appropriate standards, including compliance with any data reuse requirements, such as a regional digital library consortium, or metadata requirements to ensure compatibility with existing systems and data. In addition to selection of standards, or adherence to existing standards, metadata can be subjective and needs to be undertaken with attention to the level of specificity required for the project. Completion of successful projects demonstrates efficient processing of records balanced with an appropriate level of metadata richness. Documentation of metadata approach via a metadata application profile (MAP) as well as training materials and examples for metadata creators are also good indicators of metadata expertise.

While technical skills are valuable for metadata competencies, communication and soft skills should not be underestimated as part of this skill set. Often metadata competency is an area where collaboration is required. Many libraries have catalogers, metadata librarians or aggregators that can advise and sometimes train or provide documentation for projects. Before creating a new metadata approach from scratch, consultation can be a very effective way to gain greater competency.

At UNLV, the choice of an already processed collection eased the metadata choices for digitization. This meant there was already a certain amount of basic metadata regarding the collection; in addition, having the curator function as a subject expert engaged in prepping the collection enabled the project team to have a readymade list of prioritized subject terms, people, and corporate bodies available to input as each folder in the collection was digitized. The Building the Pipelines project manager had prior coursework in metadata, as well as experience assigning metadata in a previous internship. Using the UNLV's metadata application profile as a guide and the existing metadata procedures established for the project, the project manager was able to hone a better understanding of metadata theory applied in practice, including how to best capture the "aboutness" of these particular digital objects. The project manager also observed the importance of consistency in applying metadata by performing quality control of the studentcreated metadata. A final contributing factor in developing competency in this area is that the team, consisting of the Digital Collections librarian, the project manager, and the student assistant, had many resources available as a team to solve problems. As previously mentioned, the team met 
to review any project concerns and to pull in adjacent team members such as technical services staff, the metadata librarian, the curator, or even those with experience in programming and application development who could advise on how the metadata would appear in other systems, such as the one being developed for future digital collections. This larger group feedback was invaluable in the learning process and often touched on the more abstract concepts underpinning the tasks.

At the statewide workshops, a metadata "bootcamp" was held in which staff addressed the types of metadata standards attendees were likely to encounter, the role of a metadata application profile, how to identify an existing MAP and apply it to your collection materials, as well the value of having a subject expert available for consultation. While reuse of existing description data (e.g., finding aids or inventories) was an important topic for the first workshop, in response to feedback the second workshop's metadata bootcamps focused more on concrete steps required to make digitized images searchable regardless of other workflows or systems that might be in use. Again, this was an example of tailoring the content to the learning level of the audience. While all participants were familiar with metadata, many did not have experience using a MAP or taking interoperability into consideration. Many recognized a need to devote more time to developing this competency, regardless of project.

\section{Digital Capture}

Whether it is done in-house or outsourced to a vendor, competency in digital capture (digitization in the most specific sense) is key. This competency requires considering the materials to be digitized, how they will be displayed, and how long-term access will be provided to the digital objects. Working in-house, technical mastery is not required, but it is necessary to have a solid idea of what hardware and software capabilities are, as well as who to consult should difficulties arise (and they will). ${ }^{21}$ Mastery of this competency means having a vision for the ongoing presentation and use of the digitized material and outlining specifications to make that happen. Documenting digitization specifications is useful not only for the project manager and for future projects, but also as a training tool for students, interns, and volunteers. It can also be a source of important preservation and technical metadata ensuring files created today are sustainable into the future. In addition, a robust quality control workflow should be in place prior to uploading digital objects for display and use.

A key component of digital capture is efficiently preparing the selected materials. At UNLV, experience has taught the Digital Collections department that digitization is most successful when using materials that have already been physically processed (surveyed and arranged) and for which an inventory (finding aid) has been created. Digitization of archival materials can quickly become complicated because they are often not physically uniform or consistent, and sometimes they are grouped together for digitization into complex/compound/aggregate digital objects. Well thought-out workflows for naming and tracking individual files can make the digital capture process smoother, especially when files are related (such as the front and back of a photo, or pages of a scrapbook). This item-level documentation is critical to managing the large volume of files created in digital capture. Any conservation or preservation concerns of the physical materials should also be addressed prior to capture. Additional consultation may be required if unforeseen complications or problems arise during digital capture; item-level review may not be possible for all materials during the planning stage. For instance, there may need to be an alternate workflow for items that contain personally identifiable information or which are too fragile to undergo scanning or capture. 
There are a number of options for capturing images to create digital surrogates, including digital camera systems and a variety of scanners. Depending upon the method of capture, additional software may be needed to edit, output, and ingest the images into a digital management system. For a text-heavy collection, software for optical character recognition (OCR) makes the items fulltext searchable. For audiovisual materials, digital capture is even more complex. The local hardware, software, and procedures for capture all may require an investment in hands-on time learning and testing procedures. The repetitive nature of capturing items may also require some investigation of ergonomics or more human-friendly configurations of these variables.

At UNLV, step-by-step documentation for using the various hardware and software is key to developing staff competencies. Such documentation includes screenshots of steps in the process to contribute to comprehensive understanding and correct implementation of the workflow. Projectbased staff also make suggestions, as they move through projects, to improve current workflows. The clear documentation, repetition of tasks, access to workflows of prior digitization projects, consultation with experienced staff, and review of available resources (such as the previously mentioned FADGI website) all contributed to competency development for the project managers. Although the PIs have years of experience digitizing, it is a detailed process that can be forgotten without use and practice, and it is a competency that must be continually cultivated because of changing technology.

If it is decided to outsource digital capture, there are a number of factors to take into account in order to find the right vendor. Issues to consider include cost, company stability, prior clients and completed projects, timelines, where the work is performed, and preferred communication methods. Requesting a quote for services can be a good way to gain visibility into vendor communications, flexibility, and workflows, and will be essential if the project funds are administered in conjunction with any state or organizational purchasing rules or guidelines. Although it can be time-consuming, it is vital for the research and legwork to take place prior to starting the project (see the "Project Planning" section). In outsourcing, confidence in the digital capture partner is key. Mastery of this aspect of digitization means a comprehensive, transparent agreement, a regular flow of communication, and comfort in letting go of control over a major part of the project. Resources provided by the Northeast Document Conservation Center (NEDCC) and the Sustainable Heritage Network help to consider the pros and cons of both in-house and outsourced digital capture. ${ }^{22}$ Project management skills can also be very useful as working with a vendor shifts the needed competency from digital capture to more of a project management focus.

UNLV often employs vendors for the more challenging formats mentioned, such as oversized materials like maps and architectural drawings, and for materials like newspapers that require specialized zoning in the metadata to retrieve articles. Working with a vendor can be an informative experience, teaching communication skills, negotiation of contracts, building appropriate timelines, and quality reviewing deliverables. Some granting agencies cover a limited timeframe and outsourcing digital capture can free up an organization's time to do more librarycentric work like metadata or archival processing. For the Building the Pipelines project, most of the material in the selected collections was flat printed material that was not oversized or in challenging formats such as film/transparent material, newspapers, or media (audio/video). This led to a high comfort level for in-house digital capture as there were established procedures for the archival collection. 
At the statewide workshops, participants attended a digital capture session where they were presented with digital capture workflows and information about UNLV'S decision-making regarding digitization equipment, outsourcing vendors, and technical standards, and then they went into the digitization lab to observe the equipment in action. The digital capture bootcamp was facilitated by the head of Digital Collections, the student assistant, and the visual resources curator (who is a professional photographer). This unstructured session offered a place for attendees to preview equipment that might be suitable for their projects, get a sense of costs if they were looking to purchase equipment, and to observe the digital capture in a large-scale workflow (a specially designed rapid capture overhead camera system), a medium-scale workflow (with Digital SLR camera and copy stand), and a small-scale workflow (flatbed and map scanners). Attendees were encouraged to match equipment to their project needs or identify if outsourcing was an appropriate approach for their collection. Attendees were not able to use the equipment themselves or practice the digital capture workflows, but the small workshop format allowed them to view demonstrations in person, ask specific questions, and also see example workflows in action, which is a step above what online research or resources provide for competency development.

\section{Digital Asset Management}

Competency in digital asset management goes beyond identifying the storage capacity necessary for a project. Digital asset management includes the storage, access, and preservation of digital files and their accompanying metadata.

There are different ways to provide access to digital objects, some of the most popular being online content management systems like Omeka or digital collection management systems like CONTENTdm. ${ }^{23}$ As mentioned previously, metadata is important for staff and users to discover and locate digital objects. Competency in digital asset management requires technical knowledge of how to securely and efficiently transfer digital files that are requested, or how to provide secure and user-friendly online access. It also requires planning to ensure that whichever approach taken is sustainable and can meet demand.

Good digital preservation means planning and implementing the necessary actions to ensure that digitized resources continue to be discoverable, accessible, and usable well into the future. In the case of digitized libraries and archives materials, this means that they must be well-documented and trustworthy. Preserving digital materials includes maintaining multiple copies of files, capturing checksums to verify if the bits of a file have been corrupted over time, and in some cases, migrating file formats so that items can be viewed and used with future hardware and software.

Models for digital preservation include the Open Archival Information System (OAIS) model and the National Digital Stewardship Alliance (NDSA) levels of preservation. ${ }^{24}$ Software and tools to aid in digital preservation tasks are available, as is training. However, digital preservation is still relatively new to many in the libraries and archives profession, although some individuals and institutions have developed very sophisticated and carefully considered programs and approaches. Since digital preservation is based on technology, it will always be changing. One must not only learn and be able to implement the current standards and best practices of digital preservation, but also always keep up with changes. Success in digital preservation requires ongoing effort and evaluation. Successful digital preservation means that staff and users can find, understand, view, and use digital resources at any point in the future. 
For the grant project managers, this was the most challenging competency. While they were exposed to the complexities of digital preservation at UNLV, this process was already wellestablished, having been developed over time by the PIs and other library staff. The project managers essentially stewarded the newly digitized objects up to this point and then handed over the reins to the Digital Collections librarian. While they were free to ask questions and developed an understanding of the standards that contribute to long-term digital preservation, the project managers did not implement this particular workflow, nor did they contribute to adapting it. It is important to keep in mind that digital preservation is not an all or nothing proposition; small steps can be taken by libraries and archives professionals to address short-term digital preservation while gaining a better understanding of long-term solutions. ${ }^{25}$

Given the complexity of this competency, it was difficult to train participants in the statewide digitization workshop setting. However, UNLV's Digital Collections staff emphasized the multiplicity of options available for libraries and archives with varying levels of resources and encouraged participants to be open to starting despite ambiguity about the ultimate long-term solution for their organization. Digital collections staff also provided an overview of these options and shared the evolution of digital preservation strategies at UNLV, including suggesting some first steps such as creating an inventory of digital assets and a digital preservation plan.

Developing expertise in this competency requires in-depth research, consultation, and analysis to customize plans for local circumstances. The statewide workshops provided only an hour-long introduction to the topic and a broad overview as an example. Digital preservation is a topic that is well-addressed by other more intensive workshops though, such as the Society of American Archivists Digital Archives Specialist courses and the POWRR Institute. ${ }^{26}$

\section{SUMMARY OF COMPETENCY DEVELOPMENT: EXPERIENTIAL LEARNING VERSUS WORKSHOPS}

\section{Learning through Experience for Project Teams}

UNLV's grant projects are examples of how specific time-bound projects and grant funding can be utilized to develop both individual and organizational competencies, and to share what is learned via workshops, aiding in the professional development of others. The early career project managers advanced the most in competency development because of the opportunity for focused training and experiential learning through practice. They progressively developed digitization competencies in a number of ways, including training from the PIs, working with experienced student assistants and staff, reading locally created documentation, observing project activities and decision-making by the team, proposing solutions to challenges and testing them through trial and error, learning by doing tasks and suggesting small iterations to improve them, consulting the workflows from previous projects, and reviewing recommended resources such as the FADGI website. The project managers, though temporary employees, were treated with the same status as permanent staff and encouraged to attend meetings, ask questions, take risks, and experiment in a safe and controlled environment of learning.

Given the many multifaceted details and tasks that go into a digitization project from start to finish, it is unrealistic to expect staff to remember everything without engaging in the process themselves. Training for the grant projects broke each project down into a series of discrete steps, including preparation, digital capture, quality review, OCR transcription, metadata creation and review, and upload into the digital asset management system. Each task was reviewed and practiced in a linear manner. Given the volume of materials, basic mastery and self-sufficiency for 
the grant project staff were achieved fairly quickly. This allowed project staff to then identify areas for workflow improvements and test adjustments for increased efficiency.

Despite having just two dedicated staff, one of whom had no prior digitization experience, over 55,000 digital surrogates were created during the ten-month Building the Pipelines project, far exceeding the original goal of 10,000 images. In both grant projects the project managers were able to develop digitization competencies as a result of on-the-job experience, enriching their skill sets while also assisting UNLV Digital Collections to refine workflows for large-scale digitization projects. This in turn strengthened competencies on the organizational level, and those of the PIs.

In the best-case scenario of this kind of project, temporary staff develop valuable digitization competencies via project-based work; however, that is not always the case, and temporary project-based positions can be very harmful to the personal and professional development of workers. When undertaking a project that uses temporary labor, the organization should plan for and prioritize equitable hiring practices, fair compensation and benefits, and a positive and productive experience for temporary staff. ${ }^{27}$

\section{Learning through Experience for Organizations}

Grants are temporary in nature, so it is important that organizations who fund them and who receive funding think about the long-term implications of the temporary work. It is important for project staff to clearly document all of the details of the digitization approaches and workflows that worked successfully in the grant, as well as any problems that can be avoided. All the extra work of testing and refining new workflows completed by the project staff, can (and should) be adopted and integrated by permanent staff into the existing structure of the department or institution. One of the drawbacks for institutions undertaking grant-funded projects is that temporary staff leave and take their expertise with them. It is essential for permanent staff to not only teach, but also be open to and active in learning from the temporary staff during the project, even if the permanent staff are not doing the day-to-day work. Building opportunities for information-sharing and knowledge transfer into a project plan vastly increases the value of the grant project funding. This organizational learning is a form of accountability to the funder ensuring that projects can be sustained and that lessons learned contribute to increased capacity in the funded organization and beyond.

\section{Learning through Workshops for Professional Development}

Grant projects also pave the way to share lessons learned with colleagues via workshops or collaborative endeavors. As previously stated, conducting a day-long digitization workshop for Nevada libraries and archives institutions was a goal of both large-scale digitization grant projects undertaken by UNLV Digital Collections. Besides the metropolitan areas surrounding Las Vegas and Reno, much of Nevada is rural and sparsely populated. These workshops provided a forum for people who might not usually come together to meet and talk about their work. Many libraries and archives institutions in Nevada are small and may have limited or no experience with digitization. The workshops sought to provide an overview of large-scale digitization using UNLV projects as examples, as well as to provide practical advice related to developing digitization competencies.

The first workshop at UNLV, held in May 2018, consisted of presentations and discussions addressing the basics, methods, and challenges of large-scale digitization (see Appendix $\mathrm{C}$ for the May 2018 agenda, "Nevada Statewide Large-Scale Digitization Symposium"). The grant team surveyed participants after the workshop and received mostly positive responses. Sixteen out of 
nineteen people who completed the survey said they learned something, thirteen said they were confident and likely to apply what they learned, and eleven people said that if there was a followup workshop they would attend. The comments from the surveys showed that participants wanted more interactive activities, and many of them were not ready to implement large-scale digitization at their institutions - they wanted to learn more about the basics of digitization first. This feedback highlighted two challenges of workshop-based learning: the tendency toward passive delivery of large amounts of information and designing content for an audience with unknown or varying skill levels.

The second workshop, held in May 2019, still shared what UNLV learned about large-scale digitization during the grant project, but widened the scope to address multiple important digitization competencies, whether the project is large- or small-scale (See Appendix D for the May 2019 agenda, "Nevada Statewide Large-Scale Digitization Symposium"). Prior to the workshop, attendees were surveyed about their expertise level and topics of interest and were asked to review a project planning document with their local materials in mind. Sessions were designed as bootcamps with more extensive documentation that could be used as a template for implementation at their home organization. Participants were encouraged to ask questions and share their own experiences during the workshops and were given the option to sign up for a private consultation. The team endeavored across the workshop to allow for more interactive, hands-on learning.

Although UNLV adjusted the second workshop based on the feedback from the first, teaching practical how-to skills that are broadly applicable in a one-day workshop is challenging. Digitization is a complicated and technical undertaking that is most easily learned via hands-on experience, which is most effectively gained through repetition rather than a one-day workshop. There was not enough time or equipment for participants to actually practice parts of the digitization process themselves and so experiential learning was not always an option for every competency. Also, if participants return to an organization with different equipment, hardware, and software, there are limits to hands-on training. Another potentially problematic issue is staying up to date with the rapid technological changes that characterize digital collections. If a person gains a basic intellectual understanding of digitization via a workshop or other professional education opportunities, and then returns to their setting without starting a specific project in a timely manner, there is a risk that the knowledge they gained becomes outdated. Despite the drawbacks of workshop-based learning, workshops are still valuable venues for colleagues to come together and learn from one another. They can also provide demonstrations or hands-on learning activities that help to bridge the gap from written theory to local implementation.

\section{CONCLUSION}

Online access to libraries and archives materials is expected and increasingly necessary in order for institutions and their collections to remain vital, useful, and relevant. Ideally, digitization in libraries, archives, and museums would be a permanent functional area with specialized staff. However, many medium and smaller libraries and archives institutions do not have the capacity to sustain such an area. Competencies in the areas of project planning and management, grant writing and administration, digital capture, metadata, and digital asset management are instrumental in order to complete a successful digitization project or institute a digitization program in any setting. 
Despite the proliferation of professional workshops, online resources, literature, and conferences regarding digitization skills, it can be difficult to make time to study these materials and put such learning into practice in a way that builds to more sophisticated learning through experience. The diversity of collection materials to be digitized, the range of local circumstances, and the changing pace of technology prevent any profession-wide standardized approach to digitization education. Instead, individuals, organizations, and the profession as a whole must strategically invest in the most effective and efficient methods and opportunities for developing digitization competencies.

Locally, UNLV Digital Collections has found that experiential project-based learning is the most effective way to pilot new workflows and develop competencies. Project-based experiences, if thoughtfully designed with an eye to mentoring and supporting temporary staff, provide an opportunity for individuals to develop and practice these competencies in a hands-on way that encourages deep learning. There is a unique place for small pilot projects, modest grant projects, or one-time experimental projects to create a space for this kind of learning in almost any organization. As capacity increases, digitization projects can also be designed to develop competencies at the staff functional group level, the organizational level, or the regional level. Workshops in turn can be an opportunity for project teams or experienced individuals to share what they've learned and teach basic competencies to others. Although not as comprehensive and effective as experiential learning, workshops can provide a solid introduction to digitization competencies, especially if interactive and hands-on learning methods are incorporated and there is a willingness for organizations to remain available for consultation or questions from attendees. Workshops that have a pre- and post-session component can add continuity, and workshops that can be offered multiple times have the ability to evolve and scale. Rotating instructors, incorporating hands-on sessions, and on-going mentoring are all ways to improve workshopbased learning.

Scaffolding these approaches and sharing what is learned individually or locally with others is a way to continue to develop the capacity of libraries and archives institutions to provide global online access to unique historical materials. Although this approach is already widespread in the profession, it is important not to leave individuals or institutions with less resources behind. When planning new digitization projects or initiatives, institutions should consider adding and investing in new positions, partnerships, and regional collaborations and networks. When new permanent positions are not possible, temporary positions should be designed to be empowering and valuable for workers, rather than exploitative and harmful. In an age where technology is changing rapidly and is driven by large, well-resourced corporations, developing the profession's competencies in digitization, keeping pace with digital technologies, and remaining relevant in the information environment depends on decentralized, peer-to-peer educational opportunities that use efficient and effective methods of teaching, such as interactive and hands-on learning. 


\section{APPENDIX A}

An overview of planning and implementing digitization projects

Created by Emily Lapworth for local use, March 8, 2018. Shared at the statewide digitization workshops.

These steps were written for large-scale digitization but can be applied to any size digitization project.

1) Identify collections for digitization.

a) Brainstorm your goals for this project. Think about what you will do with these digital surrogates, and who your audience is.

b) Criteria for selection of materials

i) Formats: Start simple. If everything's the same, large-scale workflows are easier to apply. Ultimately you will need to create different workflows for each format with differing requirements. For example, print photos are digitized differently than film negatives. Text documents benefit from transcription using optical character recognition (OCR) software, while photos do not, and handwritten materials present additional discoverability challenges. When creating complex digital objects with different formats within them things can become even more complicated.

ii) Condition: fragile materials require extra handling time and possibly additional physical treatment prior to digitization.

iii) Existing arrangement and description: it is easiest if online access can directly mirror physical access, but the materials may need additional arrangement and description before digitization, depending on your goals. If the materials already have item or folder level description that is ideal. If there is any hierarchy in the existing description, especially inconsistent or complex hierarchy, consider how you will reuse that description for digital objects.

iv) Copyright: plan on providing public online access only if you own the copyright, have permission from the copyright holder, or if it is a strong case of fair use.

c) See preparation step (below) to come up with some idea of how you will undertake this project. It will likely be modified during the actual preparation, but you need to have some idea of what you will do and how you will do it in order to gather support and resources.

2) Assess the technical infrastructure needed to create, manage, provide access to, and preserve the digital files.

a) Estimate how much storage space you will need, and how much space will be needed for long-term digital preservation.

b) Make sure that your current digital preservation policies and workflows will be able to accommodate this project. Adjust them if needed.

c) Identify what equipment and software will be needed and if you already have it, can acquire it, or can use someone else's.

d) Assess if your existing workflows and systems for providing access to digital materials will be able to accommodate this project, and what changes you might need to make.

e) Technology could be a great area for collaboration! If you lack certain resources, explore opportunities to collaborate with other institutions.

3) Coordinate with other stakeholders to verify choices and plans for digitization. 
a) Find out what kind of support there is (financial, staffing, etc.) from management, administration, and the community.

b) Identify possible collaborators and discuss plans, make agreements, etc.

c) Decide who will manage and oversee the project and how different responsibilities will be distributed.

d) Identify and apply for grants if appropriate.

4) Prepare collections for digitization.

a) Arrangement: assess how are the materials physically arranged and described, and if it will help or slow down your anticipated workflows. Plan for and complete additional processing if needed.

b) Decide how you will display digitized materials. Mirroring existing arrangement is the easiest, but you also have to consider the file formats you want to create.

c) Description: figure out how you can reuse existing description. Plan metadata fields, vocabularies, prioritized subject terms and names.

d) Prepare preliminary metadata. Reuse what you already have!

e) Prepare physical materials. Verify that physical contents of the collection match existing description or inventory. Remove staples, unbind, unsleeve, flatten, etc. Identify and address any preservation or conservation issues.

f) Identify physical formats (this will help determine timeline and what equipment is needed).

g) Decide: outsource or in house?

h) Create and test workflows and procedures.

i) Create documentation for workflows and procedures (important for duration of project, for reusing for future projects, and also for future employees stewarding these digital assets to know what you did and how you did it).

j) Create and prepare systems, documents, or mechanisms to track work (it's important to stay organized, especially when dealing with a large amount of materials or a team of workers).

5) Digitize collections

a) Set up consistent file naming procedures and make sure they are followed.

b) When dealing with mixed materials in house: Depending on equipment and composition of materials, start with the easiest or what you have the most of, then take note of other formats (e.g., transparencies, oversize, etc.) that require different equipment or settings so you group them together to do later all at once.

c) Keep specifications simple if possible, especially if you have student workers doing the digitization. (For example, if you have complex digital objects with both text and photographic prints, and can digitize both materials on the same equipment without changing settings, do so. If you normally digitize text at 300 ppi but want photos at 600 ppi, rather than having the technician stop and change the settings, capture all at 600 ppi if you have the space.)

d) Auto-crop is a great tool if you have it but otherwise try to improve the efficiency of your processes with any tools at your disposal. Sometimes this can be as simple as placing the item with the correct orientation to avoid the need to manually rotate later.

e) File formats: Archival images are generally tiffs. Smaller derivative files may be necessary for access or to speed up OCR processes. Sometimes it's better to output them at the time of scanning than to batch process later.

6) Process images 
a) See above: try to improve your digitization workflows and procedures to shave time off of image processing.

b) OCR: If you have textual materials OCR transcription makes them much more accessible with less manual work into creating detailed metadata. This is especially true for large aggregations of textual documents. Resist the urge to have perfect OCR transcription.

Something is better than nothing, and when dealing with scale, you do not have the time to correct everything. Here is also an opportunity for crowdsourcing, if you have the technical resources to set it up.

c) OCR file output: depending on how you choose to display and make the digital surrogates available, you may need to output text files and/or PDF/As.

7) Describe and provide access

a) Reuse description that already exists (e.g., from an inventory or a finding aid). If a finding aid exists, make sure you are using all available information and understand how description is inherited and can be reused.

b) At the beginning of the project transform the metadata that already exists into a format you can use to describe the digital objects. You can add to this existing metadata throughout the workflow.

c) At the beginning of the project identify preferred subject terms and important names to look out for and add to digital object metadata when appropriate. This is especially important when metadata is created by students or teams or anyone unfamiliar with the subject matter of the collection. It will help ensure consistency and make faceting better for users.

d) Explore how search engine optimization (SEO) works for your public online access system. Take that into consideration when creating metadata in order to optimize discovery of the materials.

e) Make it as easy as possible for users to identify the provenance of the digital object and to find other digital objects from the same collection.

f) Consider the links between the original collection description and the digital surrogates. Consider adding digitization information or links to digital surrogates into finding aids and other records. Consider also adding a link to the finding aid in the digital object metadata. Consider using persistent identifiers, such as ARKs (Archival Resource Keys), to do this, instead of using regular URLs.

g) Find out how your access system indexes full text transcripts and how it displays different file formats. Consider if you are able/if you want to offer multiple file formats of a digital object. For example, a compound digital object that includes both text and images could be available as a collection of image files, a single PDF file, or both. Identify what would be most useful to your users.

h) Don't forget about structural, administrative, technical, and preservation metadata!

8) Implement quality control procedures (QC)

a) Have a strategy (e.g., sampling), guidelines, and goals for QC.

b) For staff performing quality control, identify the most important things to look for.

c) Decide how much time should be spent on QC.

d) Identify and acquire any automated tools that can be used.

e) Set up procedures or steps to follow when errors are found.

9) Preserve digital assets

a) You should have already planned how you will ensure access to and preservation of the digital files and metadata in the long term. Best practice is to have policies in place 
identifying what digital assets should be preserved and to what extent. Identify applicable standards and best practices, implement software and technical solutions.

b) Set up workflows and procedures to ensure that the digital files receive appropriate ongoing digital preservation treatment.

10) Publicize and promote

a) Work with administration, collaborators, and other stakeholders to publicize and promote the project.

b) Depending on your audience, social media, academic listservs, and professional organization publications can be other avenues to spread the word.

c) Set up harvesting with your regional digital library for inclusion in the Digital Public Library of America.

11) Assess

a) Web statistics can be used to track the use of online materials. See SAA/ACRL's "Standardized Statistical Measures and Metrics for Public Services" section 8 "Online Interactions" for general information on what information to collect, and the Digital Library Federation's "Best Practices for Google Analytics" for specific information on Google Analytics. If you are a CONTENTdm user, see "Google Analytics in CONTENTdm."28

b) Surveys, interviews, and focus groups are other methods that can be used to gather feedback.

c) Record and compile any oral or written feedback received from stakeholders and audiences.

d) Analyze feedback and use statistics to identify areas of success and areas for improvement. Make improvements as necessary and incorporate findings into planning for future projects. 


\section{APPENDIX B}

Digitization plan template

Template created by Emily Lapworth for local use and shared at the statewide digitization workshop.

\section{Project overview}

Collection name(s):

Collection number(s):

Link to finding aid(s) or existing description(s):

Project staff:

Project supervisor:

Research value/audience:

Goals:

Available resources: staff, money, equipment, software, etc.

Additional resources needed: staff, training, money, equipment, software, etc.

Priority level: low, medium, high. Why is this being digitized now? Part of the regular workflow, part of a grant project, or specially requested?

Publicity and promotion plans:

Assessment plans:

Estimated time frame/due date: Estimate how much time should be spent on the collection, or when it should be finished by.

Date completed/approximate hours spent:

Formats and quantity of items: e.g., seven boxes of photographic prints, three folders of flat text documents, two drawers of oversize materials, etc.

Existing arrangement \& description: How the collection is currently arranged, what description is currently available?

Copyright: What is the copyright status of the materials and can you legally digitize and provide access to them?

Restricted or sensitive materials: e.g., skip over restricted folders, digitize restricted item notice, or physically cover PII (personally identifiable information, such as social security numbers) during digitization.

Preservation issues: Any fragile or delicate materials that need extra attention? 
Notes for future/follow-up: e.g., missing items, materials that should be restricted, recommend additional processing, rehousing, digitization, metadata enhancement, etc.

\section{Preparation}

What will be digitized and what won't be? e.g., series $x$ will not be digitized at this time. It consists of audiovisual materials which would need to be outsourced.

How will items be arranged and described online? How will identifiers/file names be assigned?

e.g., each folder = a compound object, file titles from the finding aid will be used as titles for the digital objects

What physical preparation must take place before digitization? e.g., remove all staples and fasteners

\section{Digitization}

Equipment/technical specs:

- Outsourcing or in-house equipment to be used

- File types (e.g., tiffs)

- File quality (e.g., 24-bit color, 600ppi)

- File naming

Other specifications:

- Where will digital files be stored and preserved?

- How will special physical formats be handled? (e.g., scrapbooks- entire page or individual photos; magazines- entire issue or just cover? etc.)

Digital file processing

- Image correction?

- Cropping or other editing?

- OCR or transcription?

- Create derivative files?

Digital file quality control: What procedures and workflows will you put in place to ensure that everything is digitized accurately and according to the project specifications?

\section{Metadata}

What standards, fields, guidelines, and controlled vocabularies will you use?

Metadata quality control: What procedures and workflows will you put in place to ensure that all metadata is accurate, consistent, and conforms to the project specifications?

\section{Access}

How will digital objects be accessed? What systems, workflows, and procedures will be used to provide access? 


\section{APPENDIX C}

Nevada Statewide Large-Scale Digitization Symposium

Funded by LSTA

May 18, 2018

Coffee and Pastries

$9: 00-9: 30$

Digitization Lab Tour

$9: 30-10: 00$

Welcome

$10: 00-10: 15$

Opening remarks from the Dean of University Libraries and the Director of Special Collections and Archives.

Session: What is Large-Scale? [Live Streaming Begins]

$10: 15-11: 00$

This session will cover the characteristics of large-scale digitization and what sets it apart from other types of digitization projects. The UNLV Entertainment Project Team will also provide an update on the LSTA funded project they undertook to digitize over 25,000 items from UNLV's entertainment collections.

Panel: Methods for Ramping Up - Identifying Resources

$11: 00-12: 00$

There is a mandate to increase efficiency in digitization, but what resources can help you get there? This session will detail four methods to increase digitization output and address how organizations of varying resource levels can adopt them.

\section{2:00 - 1:00 Lunch}

Enjoy a catered lunch and some discussion time with colleagues from across the state and region. There will be time to walk around the room and share digitization activities at your organization via whiteboards. During lunch you can also browse the "Equipment Buffet" where we will have handouts/displays on various types of digitization equipment and outsourcing vendors.

Panel: Challenges of Digitization at a Larger Scale

$1: 00-2: 00$ 
Ramping up digitization is not as simple as merely increasing numbers. In this session we will discuss the challenges encountered each phase of digitization when scaling up and some strategies to meet the challenges.

Break [Live Streaming Ends]

$2: 00-2: 15$

During the break, browse the "Equipment Buffet" where we will have handouts/displays on various types of digitization equipment and outsourcing vendors. Using the provided worksheet, shop the buffet and rank how well each product meets your digitization needs.

Discussion: Resource 5: Statewide Collaboration (in groups)

\section{$2: 15-3: 15$}

The last session of the day will focus on an additional resource to ramping up digitization: your peers and partners right here in Nevada! We will review the notes about organizational projects and shared challenges, identify potential partnerships or collaborations, discuss grant opportunities, and work as a group to prioritize our state's most at-risk collections.

Wrap Up / Assessment

$3: 15-3: 30$

Before everyone departs for home, we will share contact information from attendees, complete a workshop evaluation and discuss follow up activities for next year. All attendees will leave with a customized plan of action for their organization.

Attendee Learning Objectives:

- Be able to define characteristics of digitization projects (mass, large-scale, boutique) and where your organization fits. Decide on the type of digitization appropriate for your organization to move toward.

- Understand pros and cons of each method and the type of resources needed to support implementation. Identify one or more method/resource for your organization to target to increase your organizational capacity.

- Understand complexities of large-scale digitization and identify one or more challenges at your organization.

- Gain perspective on projects across Nevada. Be able to identify at least one future collaborative opportunity. 


\section{APPENDIX D}

Nevada Statewide Large-Scale Digitization Workshop

Funded by LSTA

May 10, 2019

Workshop outcomes:

- Digitization Boot Camp sessions guided by survey responses

- UPR LSTA Project Update and lessons learned

- Project Consultations available

- Reflections on Statewide workshops - compare over 1 year

\section{AGENDA}

\begin{tabular}{|l|l|l|}
\hline $\begin{array}{l}\text { 8:00 }- \text { 9:00 } \\
\text { *concurrent session }\end{array}$ & Coffee and Pastries & $\begin{array}{l}\text { Digitization Lab Equipment } \\
\text { Consultations }\end{array}$ \\
\hline
\end{tabular}

\section{Welcome}

\section{9:00 - 9:15}

Opening remarks from the Dean of University Libraries

\section{Panel: Challenges of Digitization at a Larger Scale}

\section{9:15 -10:00}

What does it take to complete a large digitization project? In this case study panel presentation, we will cover the approach used in digitizing the Union Pacific Railroad water documents, including: writing the grant and selecting materials, preparing archival collections for efficient digitization, managing the project, the student technician perspective, and trouble-shooting imaging and technical issues.

Panelists: Project Manager; Curator; Digital Collections Librarian; Student Technician; Visual Resources Curator

Goal: Overview of large-scale digitization and project deliverables.

\section{Boot Camp: Preparing to Digitize}

\section{0:00 - 11:00}

Goal: Dig into the decisions needed to create a digitization plan. There will be a short presentation to go over the planning document, including asking "What makes a good project"? We will discuss labor and students and complete hands-on activities with actual collections to encourage work on individual plans.

\begin{tabular}{|l|l|l|}
\hline $\begin{array}{l}\text { 11:00 }- \text { 12:00 } \\
* \text { concurrent session }\end{array}$ & $\begin{array}{l}\text { Boot Camp: Capture } \\
\text { Images - Group A }\end{array}$ & $\begin{array}{l}\text { Boot Camp: Create } \\
\text { Metadata - Group B }\end{array}$ \\
\hline
\end{tabular}


Goal: Provide introductions to two main workflows in digitization projects: digital capture and metadata creation. There will be demonstrations, hands-on activities, and a chance to ask questions with the goal of helping to complete digitization plans.

\section{2:00 - 1:00 Lunch}

1:00 - 2:00

*concurrent session

\author{
Boot Camp: Capture \\ Images - Group B
}

Boot Camp: Create

Metadata - Group A

Goal: Provide introductions to two main workflows in digitization projects: digital capture and metadata creation. There will be demonstrations, hands-on activities, and a chance to ask questions with the goal of helping to complete digitization plans.

\section{Boot Camp - Finding External Funding}

2:00 - 2:30

Goal: Learn what opportunities exist to secure funding for your project. Hear tips on successful grant writing. Discuss possible collaboration opportunities across the state.

\section{Presenting Online Images DAMs Overview}

\section{2:30 - 3:30}

Goal: See several options for presenting your collection to an online audience. Options will highlight strategies for many staffing configurations including: solo librarian/historian, low IT resourced institutions, common systems in the profession, and complex open source development communities focused on digital asset management platform (Islandora 8).

\section{Wrap Up / Assessment}

3:30 - 3:45

Goal: Complete short survey on the workshop and ideas for future statewide events related to digitization.

One on One Consultations Available 3:45 - 4:30 


\section{ENDNOTES}

${ }^{1}$ Some examples include: “Moving Theory into Practice: Digital Imaging Tutorial," Cornell University Library/Research Department, http://preservationtutorial.library.cornell.edu/contents.html; “BCR's CDP Digital Imaging Best Practices Version 2.0," Bibliographical Center for Research, June 2008, https://sustainableheritagenetwork.org/system/files/atoms/file/bcrcdpImagingBP.pdf; "New Self-Guided Curriculum for Digitization," Digital Public Library of America, https://dp.la/news/new-self-guided-curriculum-for-digitization/; Elizabeth La Beaud, "Analysis of Digital Preservation Course Offerings in ALA Accredited Graduate Programs," SLIS Connecting 6, no. 2 (2017): 10, https://doi.org/10.18785/slis.0602.09.

${ }^{2}$ Anne Daniel, Amanda Oliver, and Amanda Jamieson, "Toward a Competency Framework for Canadian Archivists," Journal of Contemporary Archival Studies 7, Article 4 (2020): 1-13, https://elischolar.library.yale.edu/icas/vol7/iss1/4.

3 “ALA's Core Competences of Librarianship," American Library Association, 2009, http://www.ala.org/educationcareers/careers/corecomp/corecompetences; "Guidelines: Competencies for Special Collections Professionals," Association of College and Research Libraries, 2017, http://www.ala.org/acrl/standards/comp4specollect.

${ }^{4}$ Archives \& Records Association of the United Kingdom and Ireland, "The ARA Competency Framework," 2016, https://www.archives.org.uk/160-cpd/cpd/700-competency-framework.html.

${ }^{5}$ Youngok Choi and Edie Rasmussen, "What is Needed to Educate Future Digital Librarians," D-Lib Magazine 12, no. 9 (September 2006), https://doi:10.1045/september2006-choi. Youngok Choi and Edie Rasmussen, "What Qualifications and Skills are Important for Digital Librarian Positions in Academic Libraries? A Job Advertisement Analysis," The Journal of Academic Librarianship 35, no. 5 (2009): 457-67, https://doi.org/10.1016/j.acalib.2009.06.003.

${ }^{6}$ Karl-Rainer Blumenthal et al., "What Makes a Digital Steward: A Competency Profile Based on the National Digital Stewardship Residencies," LIS Scholarship Archive (2017), https://doi.org/10.17605/OSF.IO/TNMRA.

7 “MLIS Skills at Work: A Snapshot of Job Postings," San Jose State University School of Information, 2019, https://ischool.sjsu.edu/lis-career-trends-report.

${ }^{8}$ Choi and Rasmussen, "What Qualifications."

${ }^{9}$ David A. Kolb and Ronald Fry, "Toward an Applied Theory of Experiential Learning," in Theories of Group Process, ed. Cary L. Cooper (London: John Wiley, 1975), 33-57.

10 “Guidelines," Federal Agencies Digital Guidelines Initiative, http://www.digitizationguidelines.gov/guidelines/.

${ }^{11}$ Krystyna K. Matusiak and Xiao Hu, "Educating a New Cadre of Experts Specializing in Digital Collections and Digital Curation: Experiential Learning in Digital Library Curriculum," Proceedings of the American Society for Information Science and Technology 49, no. 1 (2012): 13, https://doi.org/10.1002/meet.14504901018. 
${ }^{12}$ Amy Lynn Maroso, "Educating Future Digitizers," Library Hi Tech 23, no. 2 (June 1, 2005): 187204, https://doi.org/10.1108/07378830510605151.

13 "Agenda, Digital Directions: Fundamentals of Creating and Managing Digital Collections, October 19-20, 2020, Tucson, AZ," Northeast Document Conservation Center, https://www.nedcc.org/preservation-training/dd20/agenda.

${ }^{14}$ Kim Christen and Lotus Norton-Wisla, "Digitization Project Decision-making: Starting a Digitization Project," Center for Digital Scholarship and Curation, Sustainable Heritage Network, July 1, 2017, https://sustainableheritagenetwork.org/digital-heritage/digitizationproject-decision-making-starting-digitization-project.

${ }^{15}$ Kim Christen and Lotus Norton-Wisla, "Digitization Project Decision-making: Should We Digitize? Can We Digitize?," Center for Digital Scholarship and Curation, Sustainable Heritage Network, July 1, 2017, https://sustainableheritagenetwork.org/digital-heritage/digitizationproject-decision-making-should-we-digitize-can-we-digitize-0.

16 Taylor Surface, "Getting a Million Dollar Digital Collection Grant in Six Easy Steps," OCLC Next, December 6, 2016, http://www.oclc.org/blog/main/getting-a-million-dollar-digital-collectiongrant-in-six-easy-steps/.

${ }^{17}$ Institute of Museum and Library Services, "Putting Your Best Foot Forward: Tips on Making Your Preliminary Proposal Competitive", December 31, 2015, https://www.imls.gov/blog/2015/12/putting-your-best-foot-forward-tips-making-yourpreliminary-proposal-competitive.

${ }^{18}$ Examples of project management literature relevant to cultural heritage digitization projects include: Cyndi Shein, Hannah E. Robinson, and Hana Gutierrez, "Agility in the Archives: Translating Agile Methods to Archival Project Management," RBM: A Journal of Rare Books, Manuscripts, and Cultural Heritage 19, no. 2 (2018), https://rbm.acrl.org/index.php/rbm/article/view/17418/19208; Michael Dulock and Holley Long, "Digital Collections Are a Sprint, Not a Marathon: Adapting Scrum Project Management Techniques to Library Digital Initiatives," Information Technology and Libraries 34, no. 4 (2015), https://doi.org/10.6017/ital.v34i4.5869; Michael Middleton, "Library Digitisation Project Management," Proceedings of the IATUL Conferences (1999), http://docs.lib.purdue.edu/iatul/1999/papers/20; "DLF Project Managers Toolkit," Digital Library Federation, https://wiki.diglib.org/DLF Project Managers Toolkit; Theresa Burress and Chelcie Juliet Rowell, "Project Management for Digital Library Projects with Collaborators Beyond the Library," Journal of College \& Undergraduate Libraries 24, no. 2-4 (2017), https://doi.org/10.1080/10691316.2017.1336954.

19 "Guiding Digital Success," Online Computer Library Center (OCLC), https://www.oclc.org/content/dam/oclc/contentdm/guiding digital success handout.pdf.

${ }^{20}$ Useful metadata resources include: Digital Public Library of America, "Metadata Application Profile," https://pro.dp.la/hubs/metadata-application-profile; Dublin Core Metadata Initiative, "Guidelines for Dublin Core Application Profiles," https://www.dublincore.org/specifications/dublin-core/profile-guidelines/; Oksana L. 
Zavalina et al., "Developing an Empirically-based Framework of Metadata Change and Exploring Relation between Metadata Change and Metadata Quality in MARC Library Metadata," Procedia Computer Science 99 (2016) 50-63, https://doi.org/10.1016/i.procs.2016.09.100.

21 “Guidelines: Technical Guidelines for Digitizing Cultural Heritage Materials,” Federal Agencies Digital Guidelines Initiative, http://www.digitizationguidelines.gov/guidelines/digitizetechnical.html; "Digital Preservation at the Library of Congress," Library of Congress, https://www.loc.gov/preservation/digital/.

${ }^{22}$ Robin L. Dale, “Reformatting: 6.7 Outsourcing and Vendor Relations," Northeast Documentation Conservation Center, https://www.nedcc.org/free-resources/preservation-leaflets/6.reformatting/6.7-outsourcing-and-vendor-relations; "Deciding to Outsource or Digitize InHouse," Digital Stewardship Curriculum, Center for Digital Scholarship and Curation/Sustainable Heritage Network, https://www.sustainableheritagenetwork.org/system/files/atoms/file/1.20 OutsourcingvsIn House.pdf.

23 “Omeka," Roy Rosenzweig Center for History and New Media, https://omeka.org/; "CONTENTdm: Build, showcase, and preserve your digital collections," OCLC, https://www.oclc.org/en/contentdm.html.

24 "ISO 14721:2012 Space data and information transfer systems-Open archival information system (OAIS) - Reference model," International Organization for Standardization, https://www.iso.org/standard/57284.html; "Levels of Digital Preservation," National Digital Stewardship Alliance/Digital Library Federation, https://ndsa.org//activities/levels-of-digitalpreservation/.

25 “From Theory to Action: 'Good Enough' Digital Preservation Solutions for Under-resourced Cultural Heritage Institutions”, Preserving Digital Objects with Restricted Resources (POWRR), August 2014, http://commons.lib.niu.edu/handle/10843/13610.

26 "Digital Archives Specialist (DAS) Curriculum and Certificate Program," Society of American Archivists, https://www2.archivists.org/prof-education/das; "POWRR Institutes," Digital POWRR, https://digitalpowrr.niu.edu/institutes/.

${ }^{27}$ Sandy Rodriguez et al., "Collective Responsibility: Seeking Equity for Contingent Labor in Libraries, Archives, and Museums," Institute for Museum and Library Services white paper, http://laborforum.diglib.org/wpcontent/uploads/sites/26/2019/09/Collective Responsibility White Paper.pdf.

28 SAA-ACRL/RBMS Joint Task Force on Public Services Metrics, "Standardized Statistical Measures and Metrics for Public Services in Archival Repositories and Special Collections Libraries," 2018, https://www2.archivists.org/standards/standardized-statistical-measuresand-metrics-for-public-services-in-archival-repositories; Molly Bragg et al., "Best Practices for Google Analytics in Digital Libraries: Digital Library Federation Assessment Interest Group Analytics" working group, 2015, https://doi.org/10.17605/OSF.IO/CT8BS; "Google Analytics in CONTENTdm," OCLC, 
https://help.oclc.org/Metadata Services/CONTENTdm/Get started/Google Analytics in CON TENTdm. 